\title{
In-depth proteomic profiling of left ventricular tissues in human end-stage dilated cardiomyopathy
}

\author{
Shanshan Liu ${ }^{1,2}$, Yan Xia ${ }^{4}$, Xiaohui Liu³, Yi Wang ${ }^{1,2}$, Zhangwei Chen ${ }^{4}$, Juanjuan \\ $\mathbf{X i e}^{1,2}$, Juying Qian ${ }^{4}$, Huali Shen ${ }^{1,2,3}$ and Pengyuan Yang ${ }^{1,2,3}$ \\ ${ }^{1}$ Institutes of Biomedical Sciences of Shanghai Medical School and Minhang Hospital, Fudan University, Shanghai, China \\ ${ }^{2}$ Department of Systems Biology for Medicine and School of Basic Medical Sciences, Fudan University, Shanghai, China \\ ${ }^{3}$ Department of chemistry, Fudan University, Shanghai, China \\ ${ }^{4}$ Department of Cardiology, Shanghai Institute of Cardiovascular Diseases, Zhongshan Hospital, Fudan University, Shanghai, \\ China \\ Correspondence to: Huali Shen, email: shenhuali@fudan.edu.cn
}

Juying Qian, email: qian.juying@zs-hospital.sh.cn

Pengyuan Yang, email: pyyang@fudan.edu.cn

Keywords: dilated cardiomyopathy, left ventricle, cell death, S100A1, eEF2

Received: December 15,2016 Accepted: February 12, $2017 \quad$ Published: February 25, 2017

Copyright: Liu et al. This is an open-access article distributed under the terms of the Creative Commons Attribution License 3.0 (CC BY 3.0), which permits unrestricted use, distribution, and reproduction in any medium, provided the original author and source are credited.

\section{ABSTRACT}

Dilated cardiomyopathy (DCM) is caused by reduced left ventricular (LV) myocardial function, which is one of the most common causes of heart failure (HF). We performed iTRAQ-coupled 2D-LC-MS/MS to profile the cardiac proteome of LV tissues from healthy controls and patients with end-stage DCM. We identified 4263 proteins, of which 125 were differentially expressed in DCM tissues compared to LV controls. The majority of these were membrane proteins related to cellular junctions and neuronal metabolism. In addition, these proteins were involved in membrane organization, mitochondrial organization, translation, protein transport, and cell death process. Four key proteins involved in the cell death process were also detected by western blotting, indicated that cell death was activated in DCM tissues. Furthermore, S100A1 and eEF2 were enriched in the "cellular assembly and organization" and "cell cycle" networks, respectively. We verified decreases in these two proteins in end-stage DCM LV samples through multiple reaction monitoring (MRM). These observations demonstrate that our understanding of the mechanisms underlying DCM can be deepened through comparison of the proteomes of normal LV tissues with that from end-stage DCM in humans.

\section{INTRODUCTION}

Dilated cardiomyopathy (DCM) is a type of chronic cardiovascular disease characterized by a dilation of the left or both ventricles [1]. DCM remains asymptomatic at an early stage and deteriorates gradually into heart failure (HF) without timely and effective treatment [2]. Severe cases require one or more surgical procedures, which causes an enormous burden to families and society. The progression from DCM to HF involves multiple causes and complex mechanisms [3, 4]. Remarkable progress has been made in understanding the genetic basis of DCM. Nevertheless, the set of studied genes related to DCM $(\sim 30)$ and their associated variants account for less than half of the genomic cause of DCM [5].

Most previous studies on molecular changes related to DCM focused on the transcriptome [6, 7]. Comparative proteomic analysis is a powerful diagnostic tool to determine the onset, progression, and prognosis of human diseases [8]. 2-D gel proteomics analysis was also used to reveal alterations in DCM [9]; however, the data scale was not large enough. The recent development of liquid chromatography coupled with tandem mass spectrometry (LC-MS/MS) technology in high-resolution platforms allowed for better detection of proteins expressed in low abundance $[10,11]$. MS-based quantitative proteomics 
approaches, such as iTRAQ [12], SILAC (stable isotope labeling with amino acids in cell cultures [13], MRM [14] and label-free techniques, have become increasingly useful to cardiovascular disease research [15-18]. At present, there are only a handful used biomarkers to guide clinical decision for DCM such as brain natriuretic peptide (BNP) $[19,20]$ and ST2 $[21,22]$, which can be used to predict risk of decompensation. Finding effective biomarkers and elucidating the pathogenic mechanism underlying DCM could improve the prognosis of patients. Recently, many studies have reported a large-scale cardiac proteome from whole heart [23], left ventricle (LV) [24, 25] and fetal heart [26], which revealed heart-specific proteins and differences between the human cardiac chambers (atriumenriched intracellular transport and ventricle-enriched muscle contraction). In addition, only a preliminary study on proteomic and transcriptomic alterations in DCM compared to normal LV was reported, which found 16 molecules changed conformably by proteomic and transcriptomic analysis [27].

Here, we used iTRAQ-coupled 2D LC-MS/MS to conduct an in-depth quantitative profiling of the cardiac proteome of left ventricular tissues from normal and endstage dilated cardiomyopathy hearts. Understanding the proteome will further our knowledge of the function of the cardiovascular system, thereby revealing new potential diagnostic biomarkers or therapeutic targets to treat DCM.

\section{RESULTS}

\section{Analysis of left ventricular proteomic profiling from normal human and end-stage DCM patients}

To investigate the cardiac protein alterations in end-stage DCM patients, we used quantitative proteomic analysis on normal and end-stage DCM human LVs (three samples per group), applying the iTRAQ-coupled 2D LCMS/MS method. The workflow of this study was presented in Figure 1. In total, 4263 proteins were identified and 4099 proteins were successfully quantified in the normal and end-stage DCM LVs, of which 125 proteins showed significant differences (Supplementary Table S1 \& Supplementary Table S2). The identified proteins, especially those with differential expression in end-stage DCM versus normal LVs, were imported to ExPasy, DAVID and IPA software to analyze their physicochemical properties and biological characteristics. Proteins known to participate in major biological functions were further analyzed by western blot and MRM.

Figure 2A shows a comparison between our data and several other heart proteome datasets. The histogram plot shows the comparison between our data and human LV proteome data from Heck's work and Kuster's work, which identified 3584 proteins and 4031 proteins, respectively $[24,25]$ in healthy human $L V$. To date, our $\mathrm{LV}$ proteomic profiling is one of the largest datasets for human LV. The Venn diagram shows the comparison between our data and Pandey's Human proteome map (available as an interactive web-based resource at http:// www.humanproteomemap.org), which identified 6626 proteins from adult whole heart tissue [23]. Our dataset, which focused only on LV, identified 688 extra proteins compared with Pandey's in-depth heart proteomic profiling. To further investigate human LV proteins, we analyzed their physicochemical properties and biological processes. We found that $45.3 \%$ of the identified proteins had a molecular weight $(\mathrm{MW})<=40 \mathrm{kDa}$ (Figure 2B), $52.5 \%$ were weakly acidic (pI 5.0-7.0) (Figure 2C), and $17.8 \%$ had at least one transmembrane domain $(58.4 \%$ of which had a single trans membrane domain) (Figure 2D). These LV proteins can be grossly classified in three categories: energy production (mitochondrial organization and tricarboxylic acid cycle), cardiac contraction (cellular adhesion, protein transport and muscle contraction), and protein synthesis (protein translation, mRNA catabolic process, and protein folding). Figure $2 \mathrm{E}$ listed the most representative biological processes of the LV proteins we identified.

\section{Gene ontology enrichment analysis of changed cardiac proteins in end-stage DCM}

Proteins showing over 1.2-fold in increase or at least 0.83 -fold in decrease, with $p$-value $<0.05$ were considered as differentially expressed. In total, 40 upregulated and 85 downregulated proteins were screened out for further analyses (Figure 3A). Since proteins secreted by cells in response to various stimuli are the most likely to be found in blood/plasma, it is a promising and practical approach to look for potential biomarkers in secretomes. We used SecretomeP to predict potential secreted proteins from 125 differentially the expressed proteins. We found 41 potential secreted proteins, with ten of them being previously reported as potential plasma/serum biomarkers for different diseases (Figure 3B-3C). Detailed protein descriptions and relevant literature are summarized in Supplementary Table S3. We performed gene ontology analysis on these differentially expressed proteins to elucidate their biological functions in end-stage DCM. Of all altered proteins, $20.8 \%$ functioned in mitochondria (Mt), 16.8\% were related to the cytoskeleton, $21.6 \%$ were cytoplasmic proteins, $9.6 \%$ functioned in the extracellular matrix (ECM), $11.2 \%$ in the endoplasmic reticulum (ER), and $14.4 \%$ in the nucleus. Notably, we found that $77.6 \%$ of all these changed proteins are membrane proteins (Figure 3D). We then used IPA to investigate the top five enriched canonical pathways in which these differentially expressed proteins participate, including the Amyotrophic Lateral Sclerosis pathway, semaphoring signaling in neurons, 

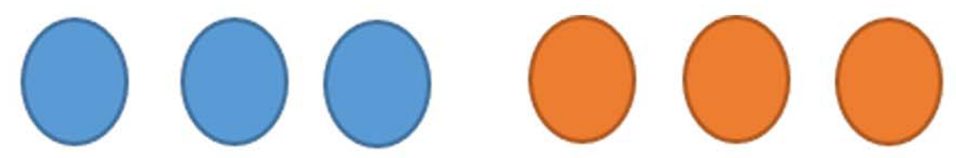

\section{N1 N2 N3 $\quad$ DCM1 $\quad$ DCM2 $\quad$ DCM3}

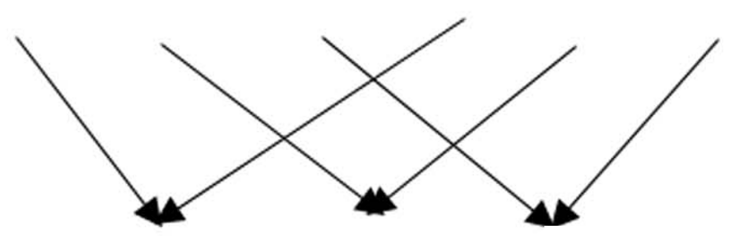

Rep $1 \quad \operatorname{Rep} 2 \operatorname{Rep} 3$

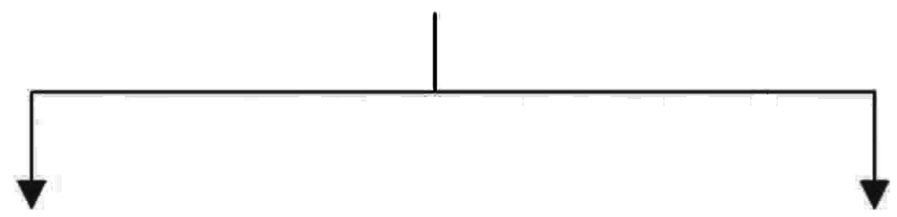

LV proteome (4263 proteins)

Filtering (125 proteins)

\section{Biological process}
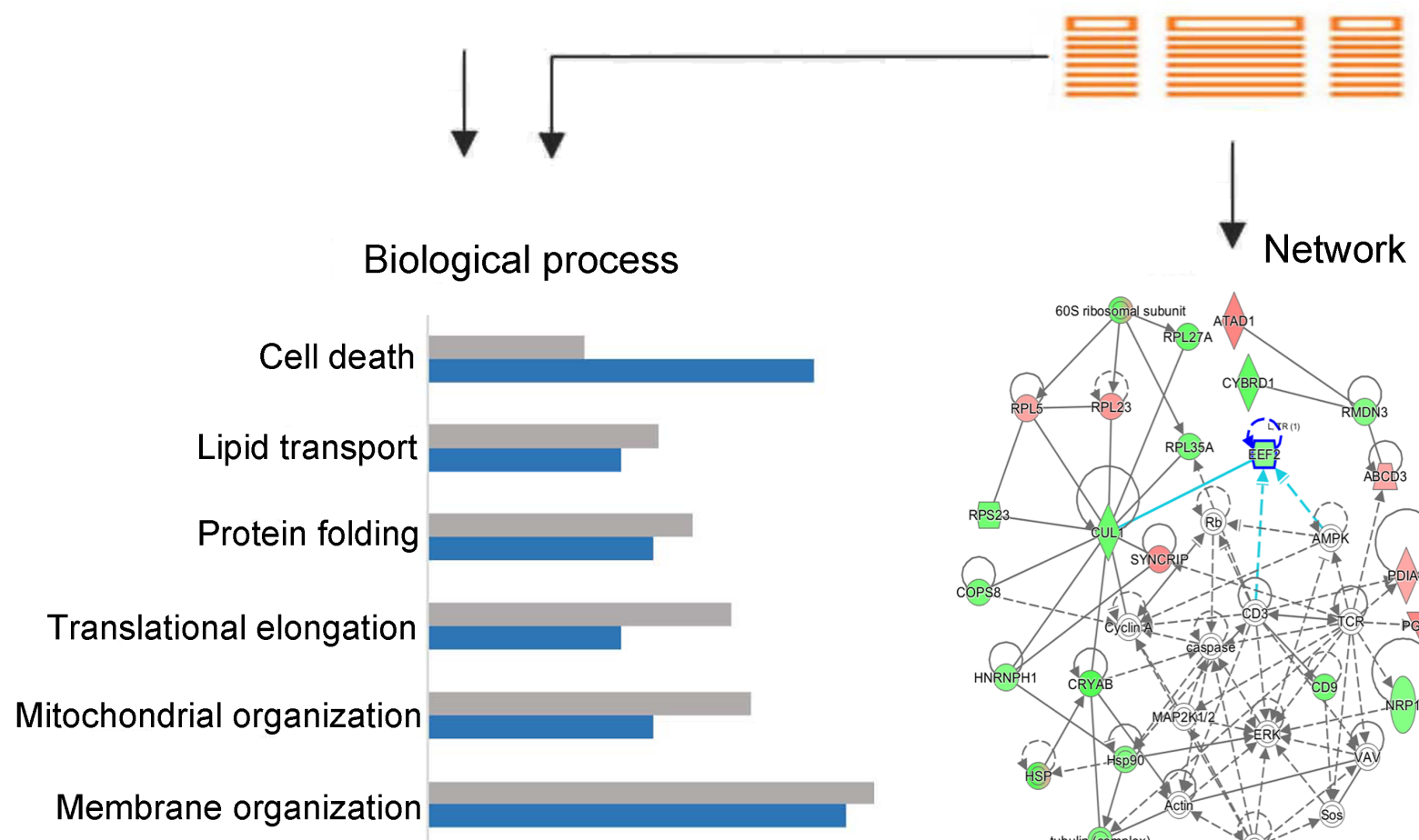

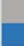
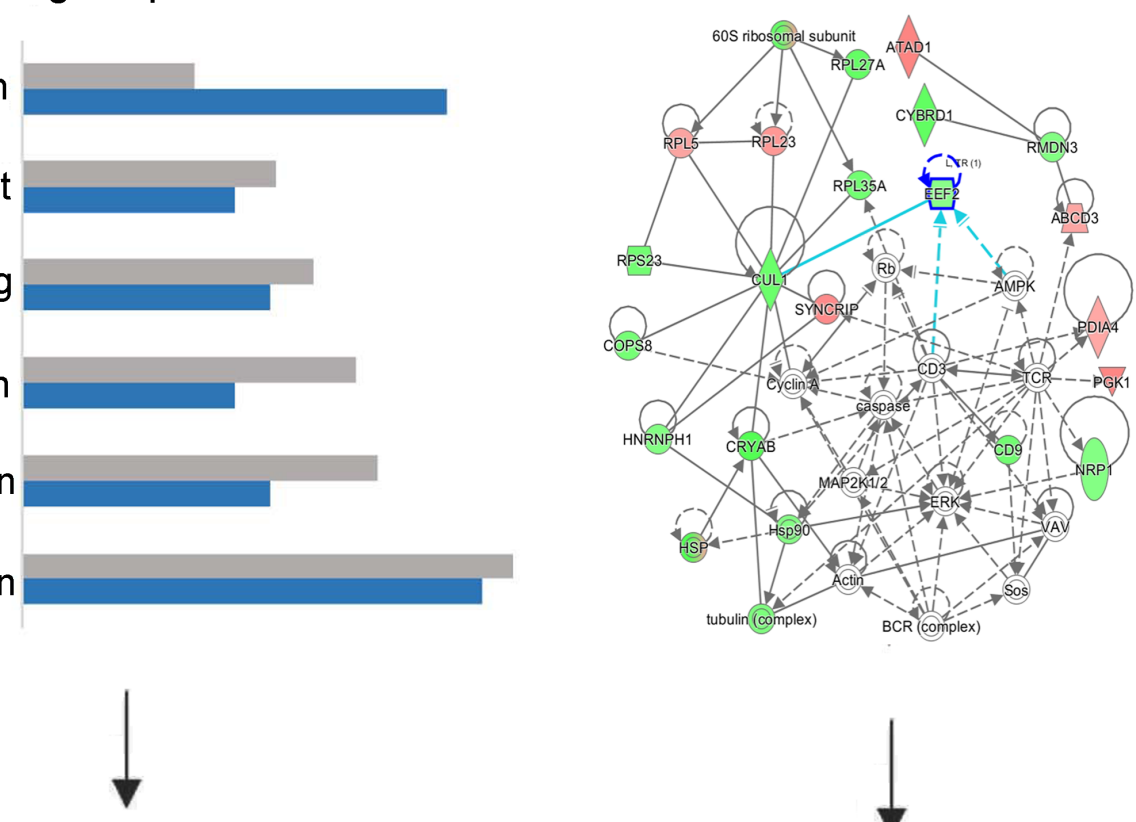

WB validation

MRM validation

Figure 1: Schematic of cardiac proteomic analysis of the left ventricular tissues from normal and end-stage dilated cardiomyopathy hearts. 
Choline degradation I, Germ-sertoli cell-cell junction, and Epithelial adherens junction (Figure 3D). Our results show that most differentially expressed proteins in endstage DCM versus normal LVs contributed to membrane organization. Furthermore, mitochondrial organization, translational elongation and protein folding processes were also prominent in DCM, followed by lipid transport and cell death processes (Figure 3E). Enrichment of
A

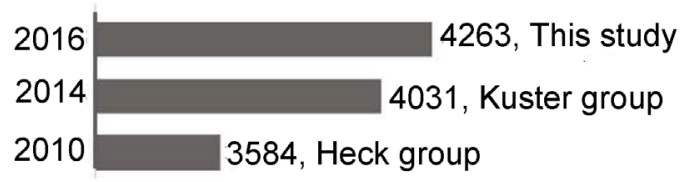

Pandey group (Adult whole heart)

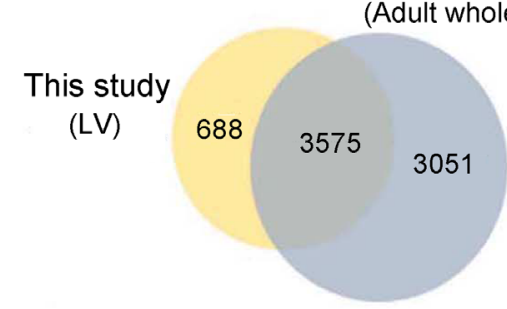

C

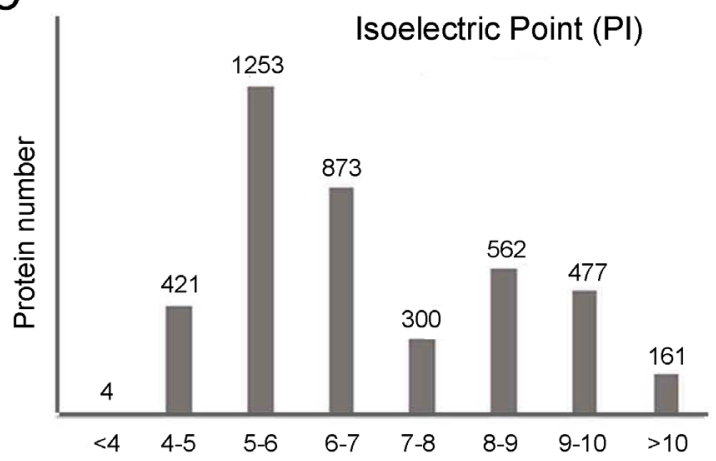

E
B

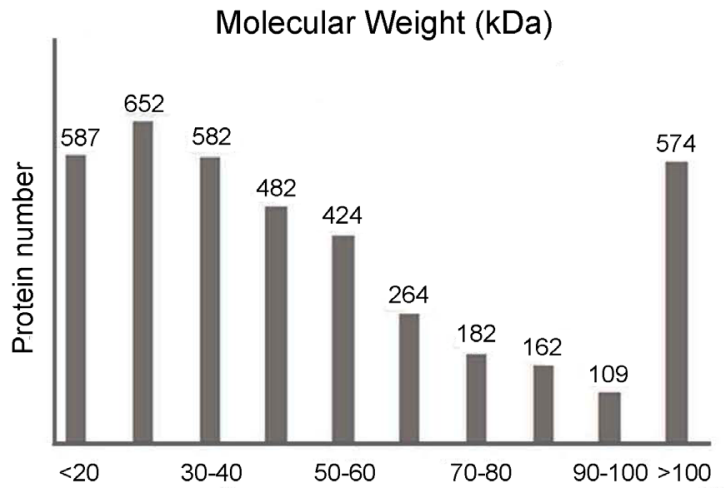

$\mathrm{D}$

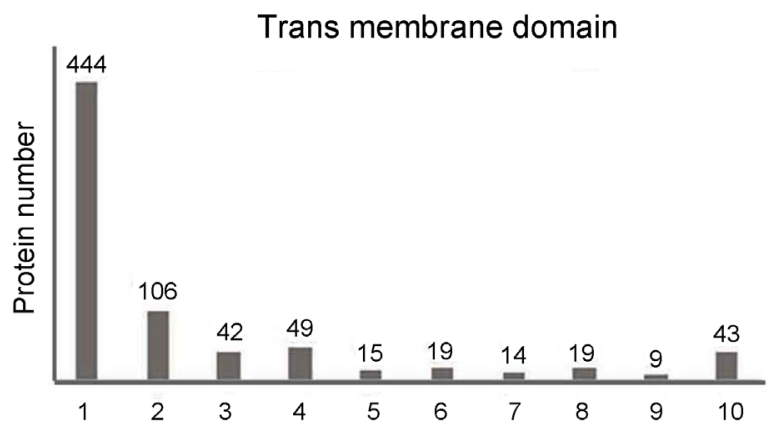

Biological Process

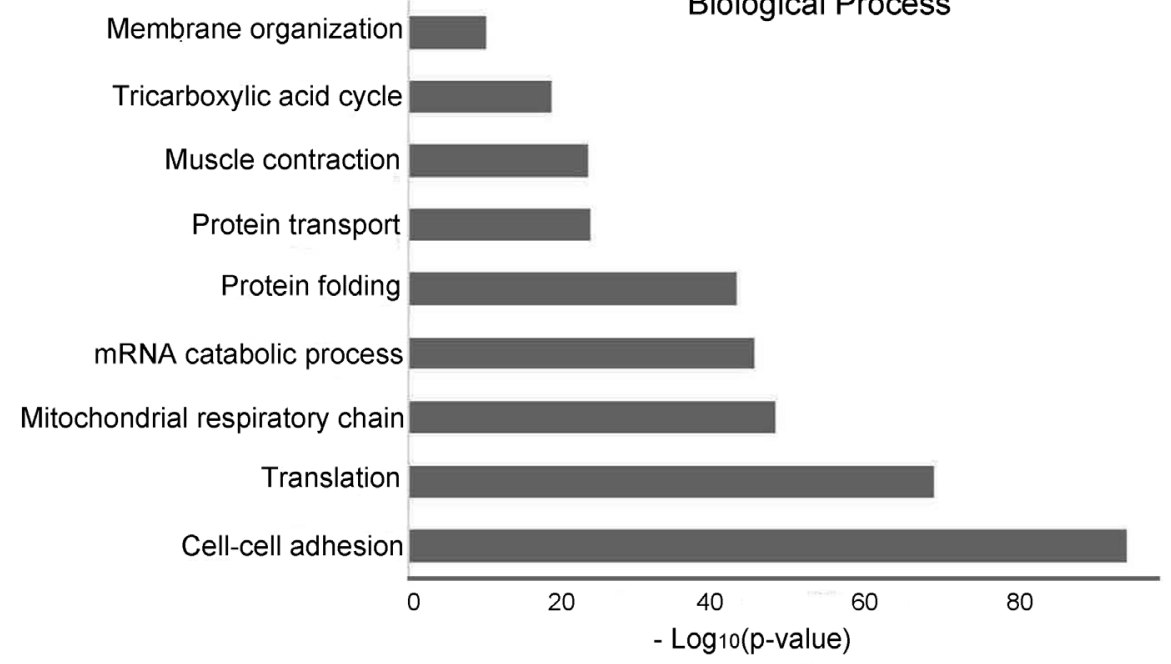

Figure 2: Physico-chemical and biological function analyses of LV proteome. A. Histogram plot and Venn diagram comparing the cardiac proteome of LV from this study with those from Heck et al., Kuster et al., and Pandey et al. B. Molecular weight (MW, in kDa) distribution of LV proteome. C. Isoelectric focusing point (pI) distributions of LV proteome. Molecular weight and isoelectric point were calculated using the online ProtParam tool available through ExPASY. D. Transmembrane domains were predicted using TMHMM 2.0. E. Biological processes of LV proteome. 
changed proteins in cell death processes indicated that the DCM samples might have developed to the end point of heart failure. We used western blot to measure the levels of four proteins relevant to cell death in every LV sample, namely Cytochrome c, Atf6, Caspase 3, and Chop. The targeted protein bands of the four proteins in LV are shown in Supplementary Figure S1. We found that these four proteins were upregulated in LV, suggesting the activation of cell death processes in our DCM samples (Figure 3F).

\section{Network analysis of changed proteins in end-stage DCM and the verification of S100A1 and eEF2 expression}

To evaluate the potential associations among the 125 differentially expressed proteins, we analyzed their possible protein-protein interactions using literaturecurated databases. Then, the differentially expressed
A
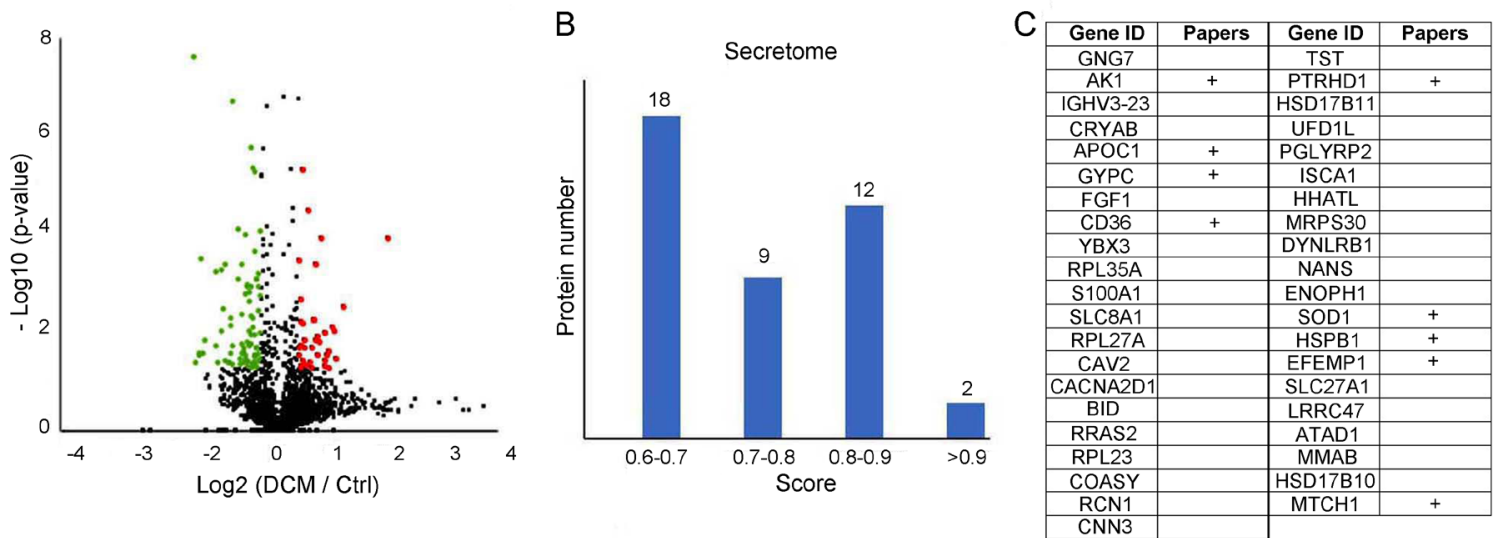

D

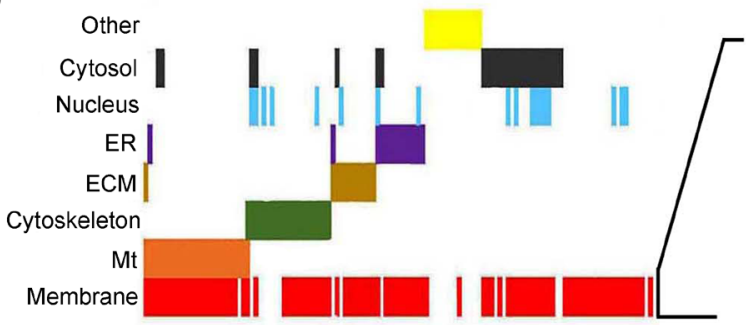

Amyotrophic Lateral Sclerosis

Semaphorin signaling in neurons

Choline degradation

Germ-sertoli cell junction

Epithelial adherens junction

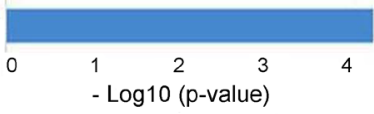

$\mathrm{F}$
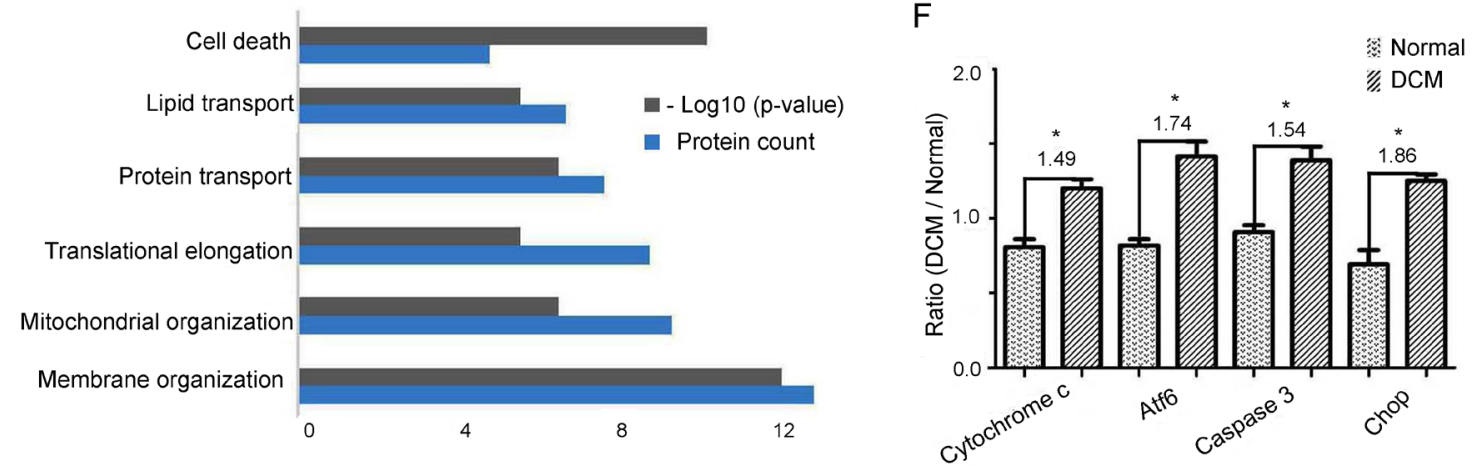

Figure 3: GO analysis of proteins differentially expressed in end-stage DCM LV compared to normal LV. A. Volcano of differentially expressed proteins. The horizontal coordinates represent the proteins with a $\log _{2}$ ratio (DCM/Control). The vertical axis is the $-\log _{10}{ }^{(p-}$ value) (p-value $<0.05$, ratio $>1.20$ shown in red and ratio $<0.83$ shown in green). Each point represents an individual protein. B. Prediction of potentially secreted by SecretomeP 2.0 from 125 differentially expressed proteins. The recommended threshold is 0.6 for mammalian sequences. C. The research status of 41 predicted secreted proteins in plasma/serum. "+" indicates that the protein has been studied in plasma/serum by literature retrieval. D. Enriched cellular compartments of differentially expressed proteins in end-stage DCM and top five enriched canonical pathways of membrane-associated proteins. E. Enriched biological processes of differentially expressed proteins in endstage DCM. The grey column represents the number of proteins in corresponding biological process, and the blue column represents the $-\log _{10}{ }^{(\text {pralue) }}$. F. Western blot validation of four key proteins, Atf6, Caspase 3, Cytochrome c, and Chop in cell death process. “*” indicates that protein alteration was significant ( $\mathrm{p}$-value $<0.05$ ). 
proteins were mainly focused on five networks (Supplementary Figure S2). The five networks can be divided into four categories: cell death and DNA replication, cellular assembly and organization, cell cycle, and lipid metabolism. We paid more attention to the two networks with the highest scores, namely the "cellular assembly and organization" and the "cell cycle" networks
(Figure 4A-B). Twenty differential proteins participated in the cellular assembly and organization network. Four proteins displayed increased expressional trend, and sixteen proteins exhibited decreased expression in endstage DCM. Nineteen differential proteins were involved in the cell cycle network. Four proteins of which were increased, and fifteen proteins were decreased. Literature
A

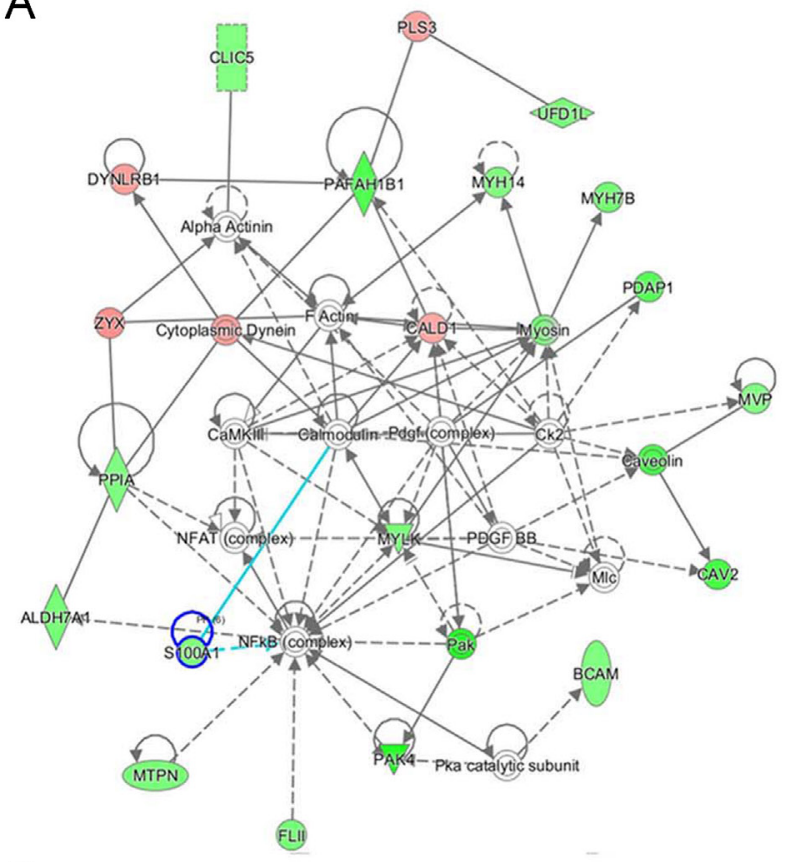

B

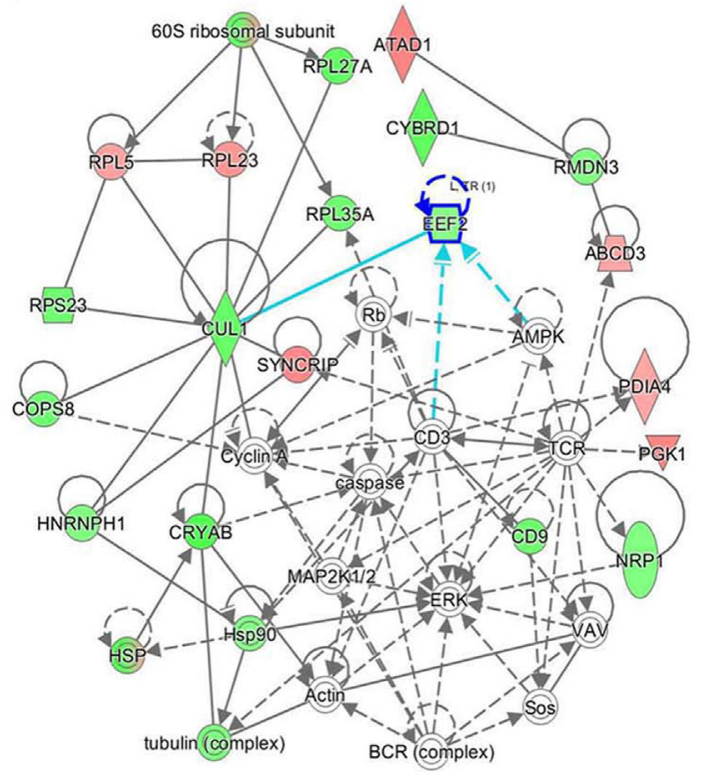

\section{ELLQTELSGFLDAQK}
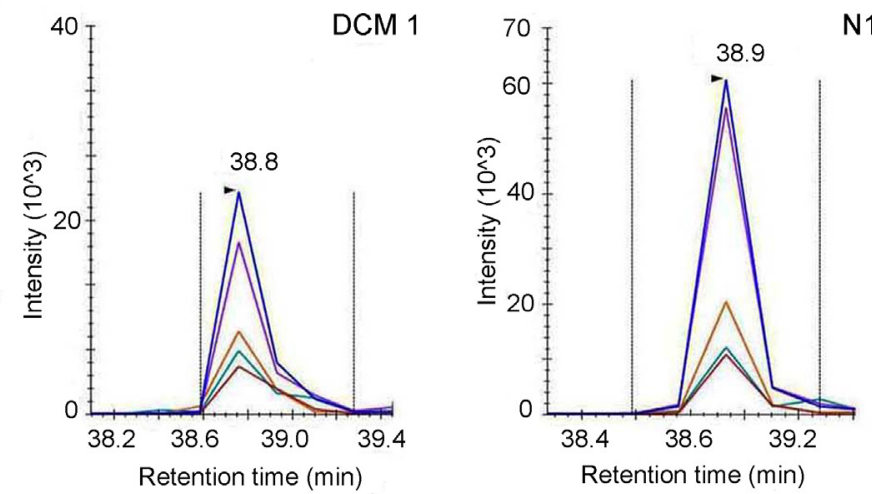

\section{GGGQIIPTAR}
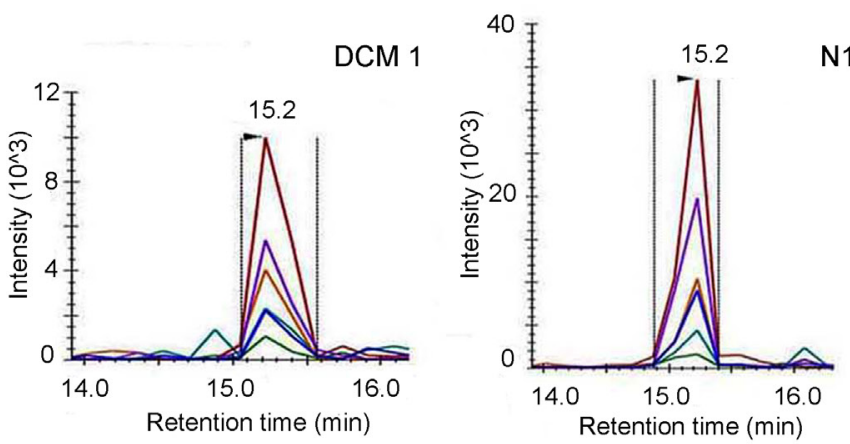

\section{E GVQYLNEIK}

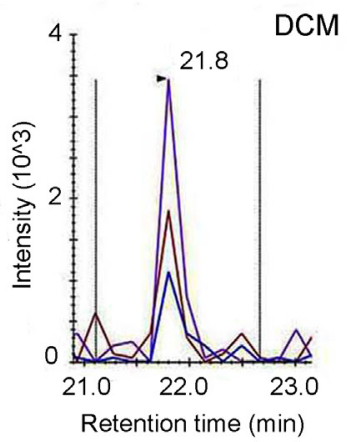

Figure 4: Verification of S100A1 and eEF2 focused on cellular assembly and organization network and cell cycle network, respectively. A. Enriched cellular assembly and organization network. Green represents downregulated proteins while red indicates upregulated ones. Color intensity correlates with fold change. Straight and dashed lines represent direct or indirect geneto-gene interactions, respectively. B. Enriched cell cycle network. C. Skyline display of the ion chromatograms for a S100A1 peptide ELLQTELSGFLDAQK. D.-E. Skyline display of the ion chromatograms of two unique peptides, GGGQIIPTAR and GVQYLNEIK, from eEF. 
retrieval to explore the relationships of these proteins in the two networks with major cardiovascular diseases are shown in Supplementary Table S4, revealing that nine of the twenty proteins in the "cellular assembly and organization" network and six of the nineteen proteins in the "cell cycle" network have been reported to be associated with Myocardial Infarction (MI), Ischemia Reperfusion (I/R), Atherosclerosis (As), Coronary Syndrome (CS) or DCM. Two down-regulated proteins in these networks, S100A1 (S100 calcium binding protein A1) and eEF2 (eukaryotic Elongation Factor 2), were validated with the MRM method. The unique peptide ELLQTELSGFLDAQK from S100A1 was screened out by following criteria established by the SRMAtlas platform (without modification, without missed cleavage, without share with others). Figure 4C \& Supplementary Figure S3 show the Skyline-extracted ion chromatograms for the peptide on six samples with its transition peaks (y8/865.4414, y7/778.4094, y5/574.3195, y4/461.2354). The two unique peptides GGGQIIPTAR and GVQYLNEIK from eEF2 were found using the same criteria. Figure 4D-E \& Supplementary Figure S4, show the Skyline-extracted ion chromatograms for the two peptide on six samples with their transitions, (y6/670.4246, y5/557.3406, y4/444.2565, b4/300.1302, b5/413.2143, b6/526.298) and (y7/907.4884, y6/779.4298, y4/503.2824), respectively. A summary of Skyline quantitation data for these product ions from the three peptides is shown in Supplementary Table S5. The average ratio (DCM/Normal) of the peptide from S100A1 is 0.85 with a $21.45 \%$ coefficient of variation $(\mathrm{CV})$. The average ratios (DCM/Normal) of the two peptides from eEF2 are $0.62(\mathrm{CV}=6.27 \%)$ for GGGQIIPTAR and 0.41 $(\mathrm{CV}=31.22 \%)$ for GVQYLNEIK. Thus, in the end-stage DCM samples, S100A1 and eEF2 were downregulated according to MRM results, which are consistent with the iTRAQ quantification results.

\section{DISCUSSION}

Heart has four different chambers, which are responsible for different functions. Reduced systolic and diastolic ability of LV is one of the major causes for DCM, yet the pathogenic mechanisms of DCM are not fully understood. Thus, we investigated alterations in left ventricular protein expression in end-stage DCM using iTRAQ-coupled 2D LC-MS/MS method. We identified a total of 4263 proteins in LV and found 125 proteins that were differentially expressed in end-stage DCM versus normal LVs. So far, our dataset is one of the largest datasets for human LV so far. Gene ontology analysis of the LV proteome highlighted the characteristic functions of heart tissue, such as muscle contraction, cell adhesion, and mitochondrial organization, etc. Cardiac contraction to deliver blood throughout the body is the core function of heart tissue. Initially, pacemaker cells in the sinoatrial node of the heart generate an action potential. Then, transmission of contractile force from one cell to another is accomplished by gap junctions and a steady supply of ATP is required to sustain cardiac contraction. Researches have shown many mutations in proteins found in junctional structures and mitochondria, which resulted in increased deterioration of the heart's pump function $[28,29]$.

In addition, we found many proteins differentially expressed in end-stage DCM are membrane proteins (Figure 3D) through quantification of more than 4000 proteins. Unsurprisingly, DCM-associated proteins were enriched in membrane organization processes when compared with the whole LV proteome (Figure 2E \& Figure 3E). Membrane proteins included ion channels and receptors, etc., which are critical for calcium storage and transmission of force among cardio-myocytes. These changed membrane proteins in end-stage DCM are involved in Amyotrophic lateral sclerosis, Semaphoring signaling in neurons and Choline degradation I. Amyotrophic lateral sclerosis can cause the death of neurons that control voluntary muscles, and is also associated with sudden cardiac death and stress-induced cardiomyopathy [30]. Semaphorins are a large family of secreted or membrane-associated glycoproteins and are usually cues to deflect axons from inappropriate regions, especially important in neural system development. Vital roles for semaphorin signaling in vascular patterning and cardiac morphogenesis have been demonstrated [31]. Choline is the precursor molecule for the neurotransmitter acetylcholine, which is involved in many functions including memory and muscle control. Choline deficiency in the clinical setting could affect the overall recovery of a patient with heart problems [32]. Previous studies have demonstrated that over-activation of the nervous system was associated with worsening heart failure and the development of both atrial and ventricular arrhythmias [33]. Thus, appropriate membrane protein-targeted mechanical exploration could be performed to modulate the cardiac nervous metabolism in DCM.

Cellular assembly and organization can provide a macromolecular infrastructure to integrate mechanical and electrical coupling within the heart, which mainly involves assembly of the cardiac disk and organization of adherens junctions [34]. Some core proteins in the CaMK II and Calmodulin networks are important for calcium signaling to maintain cardiac contraction $[35,36]$. The other core proteins in the network- PDGF complex (Platelet Derived Growth Factor) and NFאB (Nuclear factor kappa B), were important factors that participate in cellular response to extracellular stimuli $[37,38]$ (Figure 4A). In our study, S100A1 was downregulated in end-stage DCM patients, which was verified by MRM. S100A1 was predominantly found in LV with the highest protein levels [39-40]. In 1996, Remppis et al. first demonstrated that diminished S100A1 protein levels were related to dysfunctional human myocardium 
Table 1: Clinical and echocardiographic characteristics of end-stage DCM patients.

\begin{tabular}{|l|c|c|c|c|}
\hline \multicolumn{1}{|c|}{ Index } & DCM 1 & DCM 2 & DCM 3 & Average \\
\hline Age (years) & 47 & 42 & 49 & $46 \pm 3.60$ \\
\hline Gender male (\%) & 1 & 1 & 0 & $66.70 \%$ \\
\hline Prior hypertension (\%) & 0 & 0 & 0 & 0 \\
\hline Diabetes mellitus (\%) & 0 & 0 & 0 & 0 \\
\hline NYHA class & 4 & 3 & 3 & $3.3 \pm 0.58$ \\
\hline Hemoglobin (g/L) & 117 & 109 & 107 & $111 \pm 5.29$ \\
\hline Hematocrit (\%) & 35.1 & 31.9 & 30.6 & $32.5 \pm 2.32$ \\
\hline Total cholesterol (mmol/L) & 3.12 & 3.34 & 3.97 & $3.5 \pm 0.44$ \\
\hline Duration of disease (months) & 72 & 60 & 52 & $61.3 \pm 10.01$ \\
\hline Ejection fraction (\%) & 20 & 40 & 36 & $32 \pm 10.58$ \\
\hline Left ventricular end systolic diameter (mm) & 71 & 54 & 56 & $60.3 \pm 9.29$ \\
\hline Left ventricular end diastolic diameter (mm) & 77 & 68 & 68 & $71.0 \pm 5.20$ \\
\hline Left artial diameter (mm) & 57 & 70 & 34 & $53.7 \pm 18.23$ \\
\hline Pulmonary hypertension (mmHg) & 39 & 75 & 33 & $49.0 \pm 22.72$ \\
\hline
\end{tabular}

in congestive heart failure [41]. Subsequently, the relationship between $\mathrm{S} 100 \mathrm{~A} 1$ and cardiovascular events was examined in several population-based studies. A variety of animal heart failure models provided further evidence for decreased cardiac S100A1 protein levels as a molecular signature of failing myocardium in vivo [42-45]. Uncontrolled S100A1 expression has been linked to HF in human dilated cardiomyopathies as well as in various HF animal models [46]. However, the role of S100A1 in DCM remains elusive. Our findings highlight S100A1's effects in human cardiomyocytes and the potential benefits of an S100A1-targeted mechanical exploration in DCM.

The cell cycle network is related to proliferation and apoptosis and ensures appropriate heart size and development. Decreased levels of cellular cycle proteins prevent the regeneration of cardiomyocytes and result in decreased contractile ability in DCM [47]. In our study, core proteins in the cell cycle network that were differentially expressed include caspases, ERK (Extracellular signal-regulated kinase), and TCR ( $\mathrm{T}$ cell receptor) (Figure 4B). The modulation of ERK cascades can protect the heart from cell death to control the cellular growth and the development of pathological hypertrophy [48]. Caspases regulate many cellular processes from cell death to signal propagation [49]. T cell proliferation can be triggered by antigen-TCR ligation to regulate a series of immunological responses [50]. The 19 proteins we found to be differentially expressed in the cell cycle network have not been studied in the context of DCM. In our study, one of these proteins, eEF2, was related to multiple cardiovascular diseases (Supplementary Table S4). The relationships between the cell cycle and eEF2 have been examined in several population-based studies. Overexpression of eEF2 in gastrointestinal cancers impacted $\mathrm{G} 2 / \mathrm{M}$ progression in the cell cycle [51].
Previous studies have also demonstrated that eEF2 is inhibited during myocardial ischemia [52]. Furthermore, the inhibition of cell growth could be impacted via the AMPK/eEF2 kinase/eEF2 signaling pathway and slow the progression of cardiac hypertrophy [53]. In our study, the eukaryotic elongation factor eEF2 was downregulated in end-stage DCM patients as measured by iTRAQ LC-MS/ MS analysis, which was verified by MRM. The functions of eEF2 have been rarely studied in the context of cardiovascular diseases and deserve further investigation in DCM.

In summary, we performed an in-depth quantitative profiling of the cardiac proteome of left ventricular tissues from normal and end-stage dilated cardiomyopathy hearts using iTRAQ-coupled 2D LC-MS/MS. The analysis of our comprehensive proteomic data established a reference for understanding pathogenic mechanisms underlying DCM. The differentially expressed proteins we found may be valuable candidates for future biomarker discovery. Furthermore, we showed that S100A1 and eEF2 were downregulated in end-stage DCM. Future experiments should be performed to gain more insight into how these proteins impact DCM progression.

\section{MATERIALS AND METHODS}

\section{Ethics statement and tissue collection}

The study was conducted in accordance with the guidelines of the Declaration of Helsinki. All samples were obtained from Zhongshan hospital from November 2015 to January 2016, which included three end-stage DCM patients' hearts suffering from heart transplantation. Clinical history, blood tests, and electrocardiography 
were available from all the patients (Table 1). Three donor hearts that could not be transplanted for technical reasons (either because of blood type or size incompatibility) were used as controls. All donors had normal LV function and no history of myocardial disease or active infection at the time. All samples were procured from identical myocardial loci and were immediately frozen in liquid nitrogen and stored at $-80^{\circ} \mathrm{C}$.

\section{Protein extraction, in-solution digestion and pre- separation}

Heart tissues were washed and cut in PBS, then were ground under liquid nitrogen. Five times as much lysis buffer (2\% SDS, $20 \mathrm{mM}$ HEPES, $\mathrm{pH}=8.0)$ and $2 \mu \mathrm{L}$ Benzonase (Sigma Aldrich, USA) were added in the powdered tissues. Then, the suspension was ultra-sonicated for $3 \mathrm{~min}$ at $3 \mathrm{~s}$ on and $5 \mathrm{~s}$ off intervals, centrifuged at $14000 \times \mathrm{g}$ for $1 \mathrm{~h}$ at $4{ }^{\circ} \mathrm{C}$. The supernatant was collected and quantified. The proteins were reduced by $5 \mathrm{mM}$ TCEP at $56^{\circ} \mathrm{C}$ for $30 \mathrm{~min}$ and alkylated by 10 $\mathrm{mM}$ MMTS at room temperature for $30 \mathrm{~min}$, precipitated using acetone and resuspended using $50 \mathrm{mM}$ TEAB (triethylammoniun $\mathrm{m}$ bicarbonate). Lys-C (Wako, Japan) was added at a mass ratio of 1:50 (enzyme:protein) for $3 \mathrm{~h}$ at $37^{\circ} \mathrm{C}$. Then, trypsin (Promega, USA) was added to the sample at a mass ratio of 1:50 (enzyme:protein) for $12 \mathrm{~h}$. The digested peptides were desalted using a Sep-Pak C18 (Waters, USA) and concentrated using a SpeedVac. The dried peptides were resuspended in $500 \mathrm{mM}$ TEAB. After $2 \mathrm{~h}$ of iTRAQ labeling, the samples were mixed, dried, and desalted. At last, the mixture was fractionated by high $\mathrm{pH}$ reversed phase liquid chromatography (Waters, USA) and dried.

\section{Mass spectrometry analysis and database search}

The dried peptides were dissolved in buffer $\mathrm{A}(0.1 \%$ $\mathrm{FA}, \mathrm{H}_{2} \mathrm{O}$ ). Separation was performed on a reverse $\mathrm{C}_{18}$ column $\left(\mathrm{C}_{18} 3 \mu \mathrm{m}, 100 \AA 75 \mu \mathrm{m} \times 25 \mathrm{~cm}\right)$ from Thermo, with elution gradient from $8 \%$ to $38 \%$ buffer B $(0.1 \%$ FA, ACN) with a flow rate of $300 \mathrm{~nL} / \mathrm{min}$ for 2 hours by Eksigent 1D plus. The peptides were eluted into Triple TOF5600 (AB Sciex, USA) operated in positive mode with an ion spray voltage at $2.3 \mathrm{kV}$. Survey scans were acquired from 350 to $1500 \mathrm{~m} / \mathrm{z}$ while $\mathrm{MS} / \mathrm{MS}$ scans were from 100 to $1250 \mathrm{~m} / \mathrm{z}$ in high sensitivity mode. The 20 most intensive precursors were separately selected for fragmentation per cycle. For iTRAQ experiments, protein identification and quantification were performed with ProteinPilot 4.5 software. Trypsin digestion was selected. Carbamidomethyl of cysteine was specified as a fixed modification. Oxidations of methionine and acetyl of the protein $\mathrm{N}$-terminus were specified as variable modifications. A decoy database search strategy was adopted to estimate the FDR $<1 \%$ for peptide and protein identification.

\section{Biological functions and pathway analysis}

In this study, we considered only proteins that showed a 1.2-fold increase or 0.83 -fold decrease in expression, with $p$-value $<0.05$ (calculated by Student's t-test) considered as statistically significant. Annotations of biological processes and components were based on the analysis using the DAVID software (http://www.david. niaid.nih.gov). We used ingenuity pathways analysis (IPA, http://www.ingenuity.com) and calculations/assignments for imported proteins based on the literature. IPA revealed interactive networks for a set of focus proteins and biological pathways. Scores of $\geqq 2$ had at least a $99 \%$ confidence of not being generated by random chance alone.

\section{LC-MRM-MS analysis}

The analyses for all the experiments were performed on a Q-TRAP 6500 mass spectrometer (AB SCIEX, USA) equipped with a Eksigent nano LC system. MRM-MS was performed on individual samples including three normal and three DCM-associated LV. High-confidence unique peptides of the target proteins were determined from SRMAtlas database for MRMs. The equimolar calibration mixture containing 15 heavy isotope-labeled peptides (Thermo, USA) were added into each sample to normalize results for variation in retention times and peak intensities between runs. All peak area integration was performed by Skyline software version 3.0.

\section{Western blotting}

Proteins were electrophoresed in $10 \%$ polyacrylamide gel and transferred to a polyvinylidene fluoride membrane (Millipore). Protein expression was detected by immunoblotting with antibody against Atf6 (Abcam, Cambridge, UK), Caspase 3, Cytochrome c and Chop (Cell Signaling Technology, USA). After three washes, the blot was incubated with horseradish peroxidase-conjugated rabbit secondary antibody immunoglobulin G (Cell Signaling Technology, USA). GAPDH (Kangchen Biotechnology) was used as the internal control. The antigen-antibody complexes were detected using Pierce ECL Western Blotting Substrate (Thermo Fisher Scientific, Rockford, IL, USA) and visualized densitometry was performed with LAS-300 Image software (FUJIFILM, Kanagawa, Japan). 


\section{Abbreviations}

DCM: Dilated cardiomyopathy; HF: Heart failure; iTRAQ: Isobaric tags for relative and absolute quantitation; SILAC: Stable isotope labeling with amino acids in cell cultures; MRM: Multiple reaction monitoring; LV: Left ventricle; RV: Right ventricle; LA: Left atrium; RA: Right atrium; WB: Western blotting; Mt: Mitochonrion; ER: Endoplasmic reticulum; ECM: Extracellular matrix; S100A1: S100 calcium binding protein A1; eEF2: Eukaryotic elongation factor 2; ERK: extracellular signal-regulated kinase; TCR: T cell receptor; NFкB: Nuclear factor kappa B; PDGF: Platelet Derived Growth Factor.

\section{Authors' contributions}

Juying Qian, Pengyuan Yang and Huali Shen provided the idea of the paper and promoted the research. Yan Xia and Zhangwei Chen collected the tissues and performed part of the experiments. Xiaohui Liu and Yi Wang partially supported the mass spectrometry analyses. Juanjuan Xie helped analyze the data. Shanshan Liu performed the research and wrote the manuscript.

\section{ACKNOWLEDGMENTS}

This work was supported by National Key Basic Research Program of China (2014CBA02003 and 2013CB910802) and MOST 863 program (2014AA020902), as well as the Natural Science Foundation of Shanghai (16ZR1402400 and 15DZ2291100), and the Zhuo Xue Program of Fudan University.

\section{CONFLICTS OF INTEREST}

No conflicts of interest to declare.

\section{REFERENCES}

1. Burkett EL, Hershberger RE. Clinical and genetic issues in familial dilated cardiomyopathy. J Am Coll Cardiol. 2005; 45: 969-981.

2. Berul CI, McConnell BK, Wakimoto H, Moskowitz IP, Maguire CT, Semsarian C, Vargas MM, Gehrmann J, Seidman CE, Seidman JG. Ventricular arrhythmia vulnerability in cardiomyopathic mice with homozygous mutant Myosin-binding protein C gene. Circulation. 2001; 104: 2734-2739.

3. Hershberger RE, Morales A, Siegfried JD. Clinical and genetic issues in dilated cardiomyopathy: a review for genetics professionals. Genet Med. 2010: 12; 655-667.

4. Kelly M, Semsarian C. Multiple mutations in genetic cardiovascular disease: a marker of disease severity? Circ Cardiovasc Genet. 2009; 2: 182-190.

5. Hershberger RE, Hedges DJ, Morales A. Dilated cardiomyopathy: the complexity of a diverse genetic architecture. Nat Rev Cardiol. 2013; 10: 531-547.

6. Colak D, Alaiya AA, Kaya N, Muiya NP, AlHarazi O, Shinwari Z, Andres E, Dzimiri N. Left ventricular global transcriptional profiling in human end-stage dilated cardiomyopathy. Genomics. 2009; 94: 20-31.

7. Barth AS, Kuner R, Buness A, Ruschhaupt M, Merk S, Zwermann L, Kääb S, Kreuzer E, Steinbeck G, Mansmann U, Poustka A, Nabauer M, Sültmann H. Identification of a common gene expression signature in dilated cardiomyopathy across independent microarray studies. J Am Coll Cardiol. 2006; 48: 1610-1617.

8. Di Meo A, Diamandis EP, Rodriguez H, Hoofnagle AN, Ioannidis J, Lopez M. What is wrong with clinical proteomics? Clin Chem. 2014; 60: 1258-1266.

9. Roselló-Lletí E, Alonso J, Cortés R, Almenar L, MartínezDolz L, Sánchez-Lázaro I, Lago F, Azorín I, Juanatey JR, Portolés M, Rivera M. Cardiac protein changes in ischaemic and dilated cardiomyopathy: a proteomic study of human left ventricular tissue. J Cell Mol Med. 2012; 16: 24712486.

10. Olsen JV, Schwartz JC, Griep-Raming J, Nielsen ML, Damoc E, Denisov E, Lange O, Remes P, Taylor D, Splendore M, Wouters ER, Senko M, Makarov A, et al. A dual pressure linear ion trap Orbitrap instrument with very high sequencing speed. Mol Cell Proteomics. 2009; 8: 2759-2769.

11. Andrews GL, Simons BL, Young JB, Hawkridge AM, Muddiman DC. Performance characteristics of a new hybrid quadrupole time-of-flight tandem mass spectrometer (TripleTOF 5600). Anal Chem. 2011; 83: 5442-5446.

12. Ross PL, Huang YN, Marchese JN, Williamson B, Parker K, Hattan S, Khainovski N, Pillai S, Dey S, Daniels S, Purkayastha S, Juhasz P, Martin S, et al. Multiplexed protein quantitation in Saccharomyces cerevisiae using amine-reactive isobaric tagging reagents. Mol Cell Proteomics. 2004; 3: 1154-1169.

13. Ong SE, Blagoev B, Kratchmarova I, Kristensen DB, Steen H, Pandey A, Mann M. Stable isotope labeling by amino acids in cell culture, SILAC, as a simple and accurate approach to expression proteomics. Mol Cell Proteomics. 2002; 1: 376-386.

14. Anderson L, Hunter CL. Quantitative mass spectrometric multiple reaction monitoring assays for major plasma proteins. Mol Cell Proteomics. 2006; 5: 573-588.

15. Lin D, Hollander Z, Meredith A, Stadnick E, Sasaki M, Cohen Freue G, Qasimi P, Mui A, Ng RT, Balshaw R, Wilson-McManus JE, Wishart D, Hau D. Molecular signatures of end-stage heart failure. J Card Fail. 2011; 17: 867-874.

16. Wijeratne AB, Manning JR, Schultz Jel J, Greis KD. 
Quantitative phosphoproteomics using acetone-based peptide labeling: method evaluation and application to a cardiac Ischemia/Reperfusion model. J Proteome Res. 2013; 12: 4268-4279.

17. Foster MW, Yang Z, Gooden DM, Thompson JW, Ball CH, Turner ME, Hou Y, Pi J, Moseley MA, Que LG. Proteomic characterization of the cellular response to nitrosative stress mediated by S-Nitrosoglutathione reductase inhibition. J Proteome Res. 2012; 11: 2480-2491.

18. Keshishian H, Burgess MW, Gillette MA, Mertins P, Clauser KR, Mani DR, Kuhn EW, Farrell LA, Gerszten RE, Carr SA. Multiplexed, Quantitative workflow for sensitive biomarker discovery in plasma yields novel candidates for early myocardial injury. Mol Cell Proteomics. 2015; 14: 2375-2393.

19. Daniels LB, Maisel AS. Natriuretic peptides. J Am Coll Cardio. 2007; 150: 2357-2368.

20. Felker GM, Hasselblad V, Hernandez AF, O'Connor CM. Biomarkerguided therapy in chronic heart failure: a metaanalysis of randomized controlled trials. Am Heart J. 2009; 158: 422-430.

21. Januzzi JL Jr, Peacock WF, Maisel AS, Chae CU, Jesse RL, Baggish AL, O’Donoghue M, Sakhuja R, Chen AA, van Kimmenade RR, Lewandrowski KB, Lloyd-Jones DM, Wu $\mathrm{AH}$. Measurement of the interleukin family member ST2 in patients with acute dyspnea: results from the PRIDE (ProBrain Natriuretic Peptide Investigation of Dyspnea in the Emergency Department) study. J Am Coll Cardiol. 2007; 50: 607-613.

22. Manzano-Fernández S, Mueller T, Pascual-Figal D, Truong QA, Januzzi JL. Usefulness of soluble concentrations of interleukin family member ST2 as predictor of mortality in patients with acutely decompensated heart failure relative to left ventricular ejection fraction. Am J Cardiol. 2001; 107: 259-267.

23. Kim MS, Pinto SM, Getnet D, Nirujogi RS, Manda SS, Chaerkady R, Madugundu AK, Kelkar DS, Isserlin R, Jain S, Thomas JK, Muthusamy B, Leal-Rojas P, et al. A draft map of the human proteome. Nature. 2014; 509: 575-581.

24. Aye TT, Scholten A, Taouatas N, Varro A, Van Veen TA, Vosc MA, Heck AJ. Proteome-wide protein concentrations in the human heart. Mol BioSyst. 2010; 6: 1917-1927.

25. Wilhelm M, Schlegl J, Hahne H, Gholami AM, Lieberenz M, Savitski MM, Ziegler E, Butzmann L, Gessulat S, Marx H, Mathieson T, Lemeer S, Schnatbaum K, et al. Massspectrometry-based draft of the human proteome. Nature. 2014; 509: 582-587.

26. Lu ZQ, Sinha A, Sharma P, Kislinger T, Gramolini AO. Proteomic analysis of human fetal atria and ventricle. J Proteome Res. 2014; 13: 5869-5878.

27. Colak D, Alaiya AA, Kaya N, Muiya NP, AlHarazi O, Shinwari Z, Andres E, Dzimiri N. Integrated left ventricular global transcriptome and proteome profiling in human end-stage dilated cardiomyopathy. PLoS One. 2016; 11: e0162669.

28. Protonotarios N, Tsatsopoulou A. Naxos disease and carvajal syndrome: cardiocutaneous disorders that highlight the pathogenesis and broaden the spectrum of arrhythmogenic right ventricular cardiomyopathy. Cardiovasc Pathol. 2004; 13: 185-194.

29. Bayeva M, Gheorghiade M, Ardehali H. Mitochondria as a therapeutic target in heart failure. J Am Coll Cardiol. 2013; 61: 599-610.

30. Tanaka Y, Yamada M, Koumura A, Sakurai T, Hayashi Y, Kimura A, Hozumi I, Inuzuka T. Cardiac sympathetic function in the patients with amyotrophic lateral sclerosis: analysis using cardiac [123I] MIBG scintigraphy. J Neurol. 2013; 260: 2380-2386.

31. Epstein JA, Aghajanian H, Singh MK. Semaphorin Signaling in Cardiovascular Development. Cell Metab. 2015; 21: 163-173.

32. Strilakou AA, Lazaris AC, Perelas AI, Mourouzis IS, Douzis ICh, Karkalousos PL, Stylianaki AT, Pantos CI, Liapi CA. Heart dysfunction induced by choline-deficiency in adult rats: The protective role of L-carnitine. Eur $\mathrm{J}$ Pharmacol. 2013; 709: 20-27.

33. Borgquist R, Singh JP. An electrophysiologist perspective on risk stratification in heart failure: can better understanding of the condition of the cardiac sympathetic nervous system help? J Nucl Med. 2015; 56: 59S-64S.

34. Vreeker A, van Stuijvenberg L, Hund TJ, Mohler PJ, Nikkels PG, van Veen TA. Assembly of the cardiac intercalated disk during pre and postnatal development of the human heart. PLoS One. 2014; 9: e94722.

35. Nakamura TY, Iwata Y, Arai Y, Komamura K, Wakabayashi S. Activation of $\mathrm{Na}+/ \mathrm{H}+$ exchanger 1 is sufficient to generate $\mathrm{Ca} 2+$ signals that induce cardiac hypertrophy and heart failure. Circ Res. 2008; 103: 891899.

36. Fernandes IP, Oliveira-Brett AM. Calcium-induced calmodulin conformational change. Electrochemical evaluation. Bioelectrochemistry. 2017; 113: 69-78.

37. Gallini R, Lindblom P, Bondjers C, Betsholtz 1, Andrae J. PDGF-A and PDGF-B induces cardiac fibrosis in transgenic mice. Exp Cell Res. 2016; 349: 282-290.

38. Forman K, Vara E, García C, Kireev R, Cuesta S, AcuñaCastroviejo D, Tresguerres JA. Influence of aging and growth hormone on different members of the NFkB family and $\mathrm{IkB}$ expression in the heart from a murine model of senescence-accelerated aging. Exp Gerontol. 2016; 73: 114120.

39. Ehlermann P, Remppis A, Guddat O, Weimann J, Schnabel PA, Motsch J, Heizmann CW, Katus HA. Right ventricular upregulation of the $\mathrm{Ca}(2+)$ binding protein S100A1 in chronic pulmonary hypertension. Biochim Biophys Acta. 2000; 1500: 249-255.

40. Haimoto H, Kato K. S100a0 (alpha alpha) protein in cardiac muscle. Isolation from human cardiac muscle and 
ultrastructural localization. Eur J Biochem. 1988; 171: 409415.

41. Remppis A, Greten T, Schäfer BW, Hunziker P, Erne P, Katus HA, Heizmann CW. Altered expression of the Ca (2+)-binding protein S100A1 in human cardiomyopathy. Biochim Biophys Acta. 1996; 1313: 253-257.

42. Most P, Pleger ST, Völkers M, Heidt B, Boerries M, Weichenhan D, Löffler E, Janssen PM, Eckhart AD, Martini J, Williams ML, Katus HA, Remppis A, et al. Cardiac adenoviral S100A1 gene delivery rescues failing myocardium. J Clin Invest. 2004; 114: 1550-1563.

43. Most P, Seifert H, Gao E, Funakoshi H, Völkers M, Heierhorst J, Remppis A, Pleger ST, DeGeorge BR Jr, Eckhart AD, Feldman AM, Koch WJ. Cardiac S100A1 protein levels determine contractile performance and propensity toward heart failure after myocardial infarction. Circulation. 2006; 114: 1258-1268.

44. Pleger ST, Most P, Boucher M, Soltys S, Chuprun JK, Pleger W, Gao E, Dasgupta A, Rengo G, Remppis A, Katus HA, Eckhart AD, Rabinowitz JE, et al. Stable myocardialspecific AAV6-S100A1 gene therapy results in chronic functional heart failure rescue. Circulation. 2007; 115: 2506-2515.

45. Pleger ST, Remppis A, Heidt B, Völkers M, Chuprun JK, Kuhn M, Zhou RH, Gao E, Szabo G, Weichenhan D, Müller OJ, Eckhart AD, Katus HA, et al. S100A1 gene therapy preserves in vivo cardiac function after myocardial infarction. Mol Ther. 2005; 12: 1120-1129.

46. Ritterhoff J, Most P. Targeting S100A1 in heart failure. Gene Ther. 2012; 19: 613-621.

47. Zhou J, Ahmad F, Parikh S, Hoffman NE, Rajan S, Verma
VK, Song J, Yuan A, Shanmughapriya S, Guo Y, Gao E, Koch W, Woodgett JR, et al. Loss of adult cardiac myocyte GSK-3 leads to mitotic catastrophe resulting in fatal dilated cardiomyopathy. Circ Res. 2016; 118: 1208-1222.

48. Brietz A, Schuch KV, Wangorsch G, Lorenz K, Dandekar T. Analyzing ERK 1/2 signalling and targets. Mol Biosyst. 2016; 12: 2436-2446.

49. Cardona M, López JA, Serafín A, Rongvaux A, Inserte J, García-Dorado D, Flavell R, Llovera M, Cañas X, Vázquez $\mathrm{J}$, Sanchis D. Executioner Caspase-3 and 7 deficiency reduces myocyte number in the developing mouse heart. PLoS One. 2015; 10: e0131411.

50. Fernández-Arenas E, Calleja E, Martínez-Martín N, Gharbi SI, Navajas R, García-Medel N, Penela P, Alcamí A, Mayor F Jr, Albar JP, Alarcón B. $\beta$-arrestin- 1 mediates the TCRtriggered re-routing of distal receptors to the immunological synapse by a PKC-mediated mechanism. EMBO J. 2014; 33: 559-577.

51. Nakamura J, Aoyagi S, Nanchi I, Nakatsuka S, Hirata E, Shibata S, Fukuda M, Yamamoto Y, Fukuda I, Tatsumi N, Ueda T, Fujiki F, Nomura M, et al. Overexpression of eukaryotic elongation factor eEF2 in gastrointestinal cancers and its involvement in G2/M progression in the cell cycle. Int J Oncol. 2009; 34:1181-1189.

52. Liu R, Proud CG. Eukaryotic elongation factor 2 kinase as a drug target in cancer, and in cardiovascular and neurodegenerative diseases. Acta Pharmacol Sin. 2016; 37 : 285-294.

53. Chan AY, Soltys CL, Young ME, Proud CG, Dyck JR. Activation of AMP-activated protein kinase inhibits protein synthesis associated with hypertrophy in the cardiac myocyte. J Biol Chem. 2004; 279: 32771-32779. 